\title{
Update on Epidemiology and Treatment of MRSA Infections in Children
}

\author{
Michael Z. David • Robert S. Daum
}

Published online: 21 June 2013

(c) Springer Science + Business Media New York 2013

\begin{abstract}
In 2000-2010, the epidemiology of pediatric MRSA infections in the United States was transformed with an epidemic of CA-MRSA infections. We review the epidemiology of MRSA in the community and in the health care setting, including intensive care units, among infants and CF patients, and in households, as well as the impact that the CA-MRSA epidemic has had on hospitalization with MRSA infections. Risk factors for carriage, transmission, and initial and recurrent infection with MRSA are discussed. New studies on the treatment of pediatric MRSA infections and on the efficacy of MRSA decolonization are reviewed.
\end{abstract}

\section{Introduction}

Staphylococcus aureus isolates, including methicillinresistant S. aureus (MRSA) strains, are common causes of skin and soft tissue infections (SSTIs), bacteremia, osteomyelitis, and other invasive infections [1]. MRSA strains almost universally carry the mecA gene, which confers resistance to nearly all $\beta$-lactam antibiotics. $m e c A$ is carried on a genetic element, the staphylococcal chromosome cassette mec (SCCmec). Until the late 1990s, MRSA infections were almost always associated with exposure to the health care setting. The epidemiology of MRSA

\section{Z. David}

Department of Medicine, University of Chicago Medicine,

5841 S. Maryland Ave., MC6054, Chicago, IL 60637, USA

M. Z. David $(\bowtie) \cdot$ R. S. Daum

Department of Pediatrics, University of Chicago Medicine, 5841 S. Maryland Ave., MC6054, Chicago, IL 60637, USA e-mail: mdavid@medicine.bsd.uchicago.edu became complex when, in the mid-1990s, novel MRSA strains were recognized that caused infections in previously healthy children $[2,3]$. These are called community-associated (CA-) MRSA, in contrast to the healthcare-associated (HA-) MRSA that had been recognized from the early 1960s. Beginning in about 2001, an epidemic of CAMRSA infections has occurred in North America, Taiwan, Korea, and Australia, and a lower prevalence of CA-MRSA infections has been documented simultaneously in Europe, Latin America, and other parts of Asia.

CA-MRSA strains vary geographically in their genetic backgrounds, although they usually carry relatively small SCCmec types IV, $\mathrm{V}$, or $\mathrm{V}_{\mathrm{T}}$ in Taiwan, and nearly uniformly carry genes encoding the Panton-Valentine leukocidin (PVL), an otherwise unusual toxin that lyses human neutrophils. In contrast, HA-MRSA strains rarely carry the $p v l$ toxin genes. HA-MRSA strains predominantly carry SCCmec type II in North America and type III in other regions of the world. While these genetic traits can distinguish CA- from HA-MRSA, this distinction does not correlate well with the setting of onset of a MRSA infection (i.e., community or health care). CA- and HA-MRSA strains have both been found commonly in the health care setting since 2004. Both also cause infections originating in the community [4]. CA-MRSA strains tend to carry fewer non- $\beta$-lactam genetic resistance elements than HA-MRSA strains [5]. Nevertheless, the distinction between CA- and HA-MRSA is often important for clinical studies.

In the U.S. in the early twenty-first century, there have been two predominant MRSA strain types defined by pulsed field gel electrophoresis (PFGE). USA100 [usually ST5 by multilocus sequence typing (MLST) with SCCmec type II and lacking $p v l]$ is the predominant HA-MRSA strain type, and USA300 (usually ST8 with SCCmec type IV, and $p v l+$ ) is the predominant CA-MRSA type. USA300 has greater 
"fitness," virulence and transmissibility [6] compared with genotypically defined HA-MRSA isolates.

In this review, we describe studies on MRSA epidemiology and therapy in children published after the recognition of CA-MRSA, focusing on recent studies from the U.S.

\section{Maternal and Infant MRSA Colonization}

Hospital outbreaks of $S$. aureus infections, including MRSA, have long been a threat to premature and full-term newborns. In numerous studies, maternal rectovaginal MRSA colonization has been infrequently identified, suggesting that this route of transmission to newborns is not likely the major one (Table 1).

Instead of intrapartum vertical transmission, two studies suggest that transmission of MRSA or other S. aureus post-partum from mothers to infants occurs. In 2007-2009 in Memphis, Tennessee, among 50 maternalinfant pairs studied up to 4 months post-partum who had concurrent MRSA colonization, $76 \%$ had isolate pairs of the same pulsotype, and $30 \%$ of the pairs both carried USA300, most identified only long after birth [17•]. Although the molecular epidemiology of MRSA differs in Europe, a study from a Greek hospital had similar results [18].

Infants are also at risk for MRSA colonization from nonmaternal sources. In 2005-2007, among a convenience sample of healthy newborn infants in Washington State, 8/23 (35\%) had S. aureus isolated from stool, anterior nares, and/or periumbilical skin after hospital discharge at 2 weeks of age. Broth enrichment culture was not used. Two of these infants carried MRSA, but there was no MRSA nasal carriage among their parents [19]. Thus, MRSA colonization in infants can arise from many sources in the community, and, at least most of the time, it is not likely to be derived from maternal rectovaginal colonization at birth.

\section{Neonatal Intensive Care Unit (NICU) MRSA Epidemiology}

S. aureus, including MRSA, has long been a common cause of serious infections in pediatric ICUs (PICUs) and NICUs. The epidemiology of MRSA in NICUs changed in 2000-2010 as CA-MRSA, USA300 in the U.S., became more common among vulnerable patients in this setting [20• 21, 22]. Among very-low-birth-weight infants, $S$. aureus is an unusual cause of early systemic infection, but it is more common as a cause of late-onset systemic infection [23].
The emergence of USA300 in NICUs was documented in New York City and Boston. At a NICU in New York City with about 1,100 discharges per year in 2000-2008, during routine screening and 4 outbreak investigations, $8.6 \%(115 / 1,336)$ of screened neonates were colonized with MRSA. Among 93 NICU patients with actual MRSA infections, USA100 predominated during 2001-2004. USA300 became the predominant MRSA pulsotype (10/12 typed isolates) during 2007 [20•]. In 2001-2009 at the Children's Hospital of Boston, among 15,295 pediatric ICU patients, $3.2 \%(495 / 15,295)$ carried MRSA in the nares, and the proportion of MRSA isolates increased that carried SCCmec IV $(p=0.03)$, and $p v l(p=0.003)$. No isolate was $p v l+$ in 2003, but $28.9 \%$ were $p v l+$ in 2009 [21]. At Case Western Reserve University, the incidence of MRSA infections in the NICU was higher in 2006-2008 compared with 2001-2005. USA300 predominated among available MRSA isolates in 2006-2008; there were none from 2001-2005 [22].

In a Boston NICU during 2000-2007, $1.3 \%$ (102/7997) of the patients were MRSA carriers. The incidence of MRSA infections decreased from 1.79 per 1,000 patientdays in 2000 to 0.15 in 2005 with the introduction of weekly nasal and rectal surveillance cultures, but then increased to 1.26 in 2007. The antibiogram of MRSA isolates shifted from one suggesting dominance of HAMRSA in 2000-2004 to one suggesting CA-MRSA in 2006-2007 [24].

At the University of Chicago Medical Center NICU in 2007-2008, 13/614 (2.1\%) infants on admission carried MRSA in the mouth, axilla or groin. Carriage on admission was not a strong predictor of MRSA infection during the first year of life [25]. Thus, the epidemiology of MRSA infection in NICU patients is shifting and the predominant source of USA300 colonizing NICU patients is not defined; it may be staff or visitors.

\section{Pediatric Intensive Care Unit (PICU) MRSA Epidemiology}

Patients in PICUs in the United States have experienced a change in circulating MRSA strain types during the first decade of the twenty-first century. At the Johns Hopkins PICU in 2007-2008, 6 \% (72/1674) of patients had MRSA colonization. Colonized patients were younger, more likely to be black and to have been hospitalized in the previous year than those without colonization. Of the MRSA isolates obtained, $61 \%$ (40/66 tested) were USA300 or USA400, CA-MRSA strain types [26•]. Thus, as in NICUs, MRSA infections in PICUs may be predominantly caused by CA-MRSA strain types; MRSA epidemiology in the community may affect colonization trends in U.S. PICUs. 
Table 1 Studies of rectovaginal or peripartum maternal MRSA colonization, 2006-2012

\begin{tabular}{|c|c|c|c|c|c|c|c|}
\hline Location & $\begin{array}{l}\text { Year (s) of } \\
\text { testing }\end{array}$ & Population studied & $\begin{array}{l}\text { Anatomic site } \\
\text { tested (broth } \\
\text { used) }\end{array}$ & $\begin{array}{l}n \text { with } \\
\text { MRSA/ } \\
n \text { tested } \\
(\%)\end{array}$ & $\begin{array}{l}\% \\
p v l+\end{array}$ & $\begin{array}{l}\text { Genotypes identified ( } n \text { or } \\
\% \text { ) }\end{array}$ & Reference \\
\hline $\begin{array}{l}\text { New York City } \\
\text { (Columbia } \\
\text { U.) }\end{array}$ & 2005 & $\begin{array}{l}\text { Pregnant women } \\
\text { 35-37 weeks gestation }\end{array}$ & $\begin{array}{l}\text { Perirectal and } \\
\text { lower vagina } \\
\text { (Lim broth) }\end{array}$ & $\begin{array}{l}14 / 2,963 \\
(0.47 \%)\end{array}$ & NT & $\begin{array}{l}\text { SCCmec type IV (12); } \\
\text { SCCmec type V (1); } \\
\text { other SCCmec type (1) }\end{array}$ & [7] \\
\hline $\begin{array}{l}\text { New York City } \\
\text { (Columbia } \\
\text { U.) }\end{array}$ & 2009 & $\begin{array}{l}\text { Pregnant women } \\
\text { 35-37 weeks gestation }\end{array}$ & $\begin{array}{l}\text { Perirectal and } \\
\text { lower vagina } \\
\text { (Lim broth) }\end{array}$ & $\begin{aligned} 18 / 2,921 \\
(0.6 \%)\end{aligned}$ & $83.3 \%$ & USA300 (12); other (6) & [8] \\
\hline $\begin{array}{l}\text { New York City } \\
\text { (Lutheran } \\
\text { Med. Center) }\end{array}$ & & $\begin{array}{l}\text { Pregnant women } \\
\geq 35 \text { weeks }\end{array}$ & $\begin{array}{l}\text { Rectovaginal } \\
\text { culture }\end{array}$ & $\begin{array}{l}7 / 6,626 \\
(0.1 \%)\end{array}$ & NT & NT & [9] \\
\hline Nashville, TN & 2006 & $\begin{array}{l}\text { Pregnant women } \\
35-37 \text { weeks gestation }\end{array}$ & $\begin{array}{l}\text { Rectovaginal } \\
\text { culture (Lim } \\
\text { broth) }\end{array}$ & $\begin{array}{l}26 / 250 \\
\quad(10.4 \%)\end{array}$ & $23 \%$ & $\begin{array}{l}\text { SCCmec type IV (7); other } \\
\text { type (19) }\end{array}$ & {$[10]$} \\
\hline $\begin{array}{l}\text { Birmingham, } \\
\mathrm{AL}\end{array}$ & 2003-2006 & $\begin{array}{l}\text { Pregnant women } \\
35-37 \text { weeks gestation }\end{array}$ & Anovaginal (nb) & $\begin{array}{c}202 / 5,732 \\
(3.5 \%)\end{array}$ & NT & NT & [11] \\
\hline Orlando, FL & 2005-2006 & $\begin{array}{l}\text { Pregnant women admitted } \\
\text { to labor and delivery } \\
\text { delivering within } 24 \mathrm{~h}\end{array}$ & $\begin{array}{l}\text { Vaginal and } \\
\text { nares culture } \\
(\mathrm{nb})\end{array}$ & $\begin{array}{l}6 / 288 \\
\quad(2.1 \%)\end{array}$ & NT & $\begin{array}{l}\text { SCCmec type IV (4); } \\
\text { SCCmec type II (2) }\end{array}$ & {$[12]$} \\
\hline South Carolina & 2009-2010 & $\begin{array}{l}\text { Pregnant women admitted } \\
\text { for pre-term delivery }\end{array}$ & $\begin{array}{l}\text { Vulva, } \\
\text { rectovaginal, } \\
\text { and nares } \\
\text { culture }(\mathrm{nb})\end{array}$ & $\begin{array}{l}15 / 422 \\
(3.6 \%)\end{array}$ & NT & $\mathrm{NT}^{\mathrm{b}}$ & [13] \\
\hline Portland, OR & 2009 & $\begin{array}{l}\text { Pregnant women } \\
\text { 35-37 weeks gestation }\end{array}$ & $\begin{array}{r}\text { Rectovaginal } \\
\text { (Lim broth) }\end{array}$ & $\begin{array}{r}26 / 1,488 \\
(1.7 \%)\end{array}$ & NT & NT & [14] \\
\hline Cleveland, $\mathrm{OH}$ & $2005-2006$ & $\begin{array}{l}\text { Pregnant women admitted } \\
\text { to labor and delivery }\end{array}$ & $\begin{array}{l}\text { Vagina and } \\
\text { nares (nb) }\end{array}$ & $\begin{array}{l}2 / 96 \\
(2.1 \%)\end{array}$ & NT & NT & {$[15]$} \\
\hline Maywood. IL & 2007-2009 & $\begin{array}{l}\text { Pregnant women admitted } \\
\text { to labor and delivery }\end{array}$ & $\begin{array}{l}\text { Nares (PCR } \\
\text { only) }\end{array}$ & $\begin{array}{c}39 / 2,254 \\
(2 \%)\end{array}$ & NT & NT & [16] \\
\hline
\end{tabular}

$N T$ not tested, $S T$ sequence type

${ }^{a}(n b)$ indicates that broth enrichment culture was not used; $(b)$ indicates that broth enrichment culture was used

b PFGE was reported for some neonatal isolates but results were not reported for maternal isolates

\section{Trends in Pediatric MRSA-Associated Hospitalization and Infection Incidence}

As early as 2003, young age was determined to be a risk factor for CA-MRSA infection compared with HA-MRSA [5], and newer evidence has continued to support this association. In a retrospective study in New York City in 1997-2006, age <18 years was a risk factor for CAMRSA-related hospitalization (adjusted OR 1.29, $p<0.01)$ [27]. In Orange County, California, in 2008-2009, hospitalized children with a MRSA infection were more likely than adults to be infected by a CA-MRSA strain type [28]. In a meta-analysis, the percent of CAMRSA among all MRSA infections in U.S. children plateaued at about $70 \%$ in 1995, far earlier than among adults, for whom it was still rising in 2010 [29].
In the U.S. [30-32] and Canada [33], the epidemic of CA-MRSA was associated with a rapid increase in hospital stays for SSTIs among children in 1995-2010. Using the National Hospital Discharge Survey, a federal database that includes billing data from a sample of U.S. hospital stays, it was estimated in 1996-2006 that 616,375 children were hospitalized with a primary diagnosis of SSTI. The incidence increased from $<1$ in 1996 to 25.5 per 100,000 in 2006 [30].

In California, data from a state-wide hospital discharge database showed a rapid rise in population-based incidence of pediatric hospitalizations for $S$. aureus infections from 1985 to 2009 . In $1985,49 / 100,000$ children were hospitalized for a $S$. aureus infection. With the emergence of CA-MRSA infections, the incidence increased by $>50 \%$, peaked at 83/100,000 in 2006 and then decreased to 
73/100,000 in 2009. This last decrease demonstrates a common trend in a number of epidemiologic studies in adults and children after 2006. The increase to 2006 was driven by MRSA SSTIs, infections in children 1-24 months of age and in black children of all ages. In 2000-2009, the incidence of MRSA infections in hospitalized children increased from 3 to 35/100,000 children per year. Hospitalizations for community-onset pediatric MRSA infections increased 27.7-fold in 2000-2006 [34••].

Studies based on laboratory data have similarly shown an increase in MRSA infections. A laboratory-based surveillance study at UCLA in 2001-2010 found that, among inpatient and outpatient pediatric SSTI cultures, $33.2 \%$ $(1,119 / 3,372)$ grew $S$. aureus, and $40.1 \%(449 / 1,119)$ were MRSA, with a peak (49 \%) in 2005. The percent of MRSA among outpatient $S$. aureus SSTIs changed little during 2004-2007 (annual mean, 47.8\%), prior to a slow decline in 2008-2010 [35]. Thus, the epidemic of CA-MRSA infections had an impact on hospitalizations for children in the U.S., both as a cause of infections in the community and in the health care setting.

\section{MRSA Colonization in Children: Geographic Variation and Risk Factors}

The prevalence of asymptomatic carriage of MRSA among healthy children showed great geographic variation, as did the predominant strain types of MRSA, in 2000-2010 (Table 2). In Nashville, TN, nasal MRSA colonization in healthy children increased from 0.8 to $9.2 \%$ in 2001-2014 [49], but most subsequent U.S. studies have reported a lower prevalence. Studies from other countries have demonstrated carriage prevalence ranging from $<1$ to $15.1 \%$ (Table 2).

The household is likely an important site of transmission among U.S. children and their close contacts, as suggested by studies in Minnesota [50] and Michigan [51], and a study in adults and children in Los Angeles and Chicago [52]. Home visits were made to 236 children in Minnesota after convalescence from a CA-MRSA infection. Patients and their 712 household contacts underwent nasal cultures for MRSA colonization without broth enrichment. Totals of $13 \%(29 / 236)$ of case patients and $12 \%(82 / 712)$ of contacts carried MRSA. At least one contact in $25 \%$ (58/ 236) of households carried MRSA. $76 \%$ of colonizing MRSA isolates obtained from case-patients and $87 \%$ from their contacts shared the PFGE pulsotype of the index infection isolate from that household. Risk factors for household contacts to be MRSA-colonized included assisting the case patient in bathing or sharing of lotions with the case patient. The risk of colonization was decreased among contacts who used antibacterial soap
[50]. The study was limited by lack of extranasal cultures given the frequently exclusive extranasal CA-MRSA colonization identified in other studies [52].

In Detroit, MRSA nasal carriage was more frequent in 2007-2008 among pediatric inpatients with CA-MRSA infection $(23 \%, 18 / 77)$ than among uninfected control children $(3.9 \%, 3 / 77)(p \leq 0.001)$ admitted to the same hospital. Similarly, MRSA carriage was more common among household contacts of patients $(58 \%, 14 / 24)$ compared with household contacts of controls $(6.9 \%, 2 / 29)$ $(p=0.001)$. At least one household contact in the infection patients' households had a similar PFGE pulsotype to the index patient in 10/14 households [51], suggesting that there is likely to be household transmission of CA-MRSA.

S. aureus carriage on an individual may be polyclonal. A study from Illinois of 125 children tested for nasal carriage of $S$. aureus prior to surgery demonstrated that $26 \%$ (32/ 125 ) carried at least two $S$. aureus strain types as defined by multi-locus variable-number tandem-repeat fingerprinting [53•]. This suggests that decolonization in children may result in unintended consequences because some strain types of $S$. aureus are commensals and not major pathogens.

In the U.S., the carriage of closely related MRSA isolates by several household members suggests that the household is likely an important site of MRSA transmission. Given the complex strain type dynamics of $S$. aureus colonization in households [52] and on individuals [53•], further research is needed to determine how to control transmission in households and among children generally, assessing for unintended consequences of decolonization regimens or other interventions.

\section{Risk Factors for CA-MRSA Infection}

Risk factors for CA-MRSA infection have recently been examined in children, and included obesity [54], chronic skin disease, especially eczema [54], previous SSTI, a close contact with a recent SSTI [54, 55•], and recent use of antibiotics $[54,56]$. Interventions to protect these high-risk children have not been widely studied.

Native Hawaiians and Pacific Islanders (NHPI) have a high risk for $S$. aureus infections. In a study of children on Maui, Hawaii attending clinics in 2008-2009, cases with a S. aureus SSTI [28/71 (39.4\%) had MRSA and 43/71 $(60.6 \%)$ had MSSA], were compared with age-matched controls without an SSTI. Risk factors for a $S$. aureus SSTI were having a household contact with a $S$. aureus SSTI, abrasions or wounds of the skin, and being overweight. Among NHPI, the latter two risk factors were significant as were antibiotic use within 6 months and a history of eczema or another chronic skin disorder [54]. It is not 
Table 2 Studies on MRSA Carriage in Healthy Children, 2009-May 2013

\begin{tabular}{|c|c|c|c|c|c|c|c|}
\hline Location & $\begin{array}{l}\text { Year }(s) \text { of } \\
\text { testing }\end{array}$ & Place of testing & $\begin{array}{l}\text { Anatomic site } \\
\text { tested (broth } \\
\text { used) }\end{array}$ & $\begin{array}{l}n \text { with } \\
\text { MRSA/ } \\
n \text { tested } \\
(\%)\end{array}$ & $\begin{array}{l}\% \\
p v l+\end{array}$ & Genotypes identified ( $n$ or $\%$ ) & Reference \\
\hline $\begin{array}{l}\text { North } \\
\text { Carolina } \\
\text { and } \\
\text { Virginia }\end{array}$ & 2007-2009 & $\begin{array}{l}24 \text { child care } \\
\text { centers }\end{array}$ & Nares (nb) & $\begin{array}{l}15 / 163 \\
(1.3 \%)\end{array}$ & $40 \%$ & $\begin{array}{l}\text { ST5 (6); ST8/IV/pvl+ (5); ST1532 } \\
\text { (1); ST231 (1); ST97/IV/pvl-(1); } \\
\text { ST5slv (1) }\end{array}$ & [36] \\
\hline $\begin{array}{l}\text { Galveston, } \\
\text { Texas }\end{array}$ & Not stated & $\begin{array}{l}\text { Children at a } \\
\text { child care } \\
\text { facility at a } \\
\text { medical center }\end{array}$ & $\begin{array}{l}\text { Nares, axillae, } \\
\text { inguinal, } \\
\text { perirectal area, or } \\
\text { oropharynx (b) }\end{array}$ & $\begin{array}{l}7 / 104 \\
\quad(6.7 \%)\end{array}$ & $57 \%$ & $\begin{array}{l}\text { USA300 (4); USA100 (2); USA600 } \\
\text { (1) }\end{array}$ & {$[37]$} \\
\hline $\begin{array}{l}\text { Seoul, } \\
\text { South } \\
\text { Korea }\end{array}$ & 2008 & $\begin{array}{l}\text { Healthy children } \\
\text { in } 7 \text { day care } \\
\text { centers, } \\
1-6 \text { years old }\end{array}$ & Nares (b) & $\begin{array}{l}40 / 428 \\
\quad(9.3 \%)\end{array}$ & $0 \%$ & $\begin{array}{l}\text { ST72/IV (23); ST72/II (6); ST1765/ } \\
\text { IV (4); ST1765/II (2); other (5) }\end{array}$ & {$[38]$} \\
\hline Hong Kong & 2009-2010 & $\begin{array}{l}\text { 2- to } 5 \text {-year-old } \\
\text { children at day } \\
\text { care centers }\end{array}$ & $\begin{array}{l}\text { Nares or } \\
\text { nasopharynx (b) }\end{array}$ & $\begin{array}{l}28 / 2,211 \\
(1.3 \%)\end{array}$ & NT & $\begin{array}{l}10 \text { STs: ST59 (9); ST45 (7); ST10 (4) } \\
\text { other ST (8). } 2 \text { SCCmec types: } \\
\text { SCCmec type IV (13); SCCmec type } \\
\text { V (15) }\end{array}$ & [39] \\
\hline $\begin{array}{l}\text { Brussels, } \\
\text { Belgium }\end{array}$ & $2006-2008$ & 11 kindergartens & $\begin{array}{l}\text { Nasopharynx, } \\
\text { tested } 3 \text { times } \\
\text { over } 12 \text { months } \\
\text { (unk) }\end{array}$ & $\begin{array}{r}11 / 333 \\
(3 \%)\end{array}$ & $0 \%$ & 7 spa types; 6 STs & {$[40]$} \\
\hline $\begin{array}{l}\text { Portugal, } 3 \\
\text { regions }\end{array}$ & $\begin{array}{l}2006, \\
2007 \\
2009\end{array}$ & $\begin{array}{l}\text { Children } 6 \text { years } \\
\text { old and younger }\end{array}$ & Nasopharynx (nb) & $\begin{array}{l}3 / 2,100 \\
\quad(<1 \%)\end{array}$ & $0 \%$ & $\begin{array}{l}\mathrm{ST} 939 / \mathrm{IVa} / p v l-/ \mathrm{t} 324(1) ; \mathrm{ST} 72 / \mathrm{IVc} / \\
p v l-/ \mathrm{t} 148(1) ; \mathrm{ST} 931 / \mathrm{VI} / p v l-/ \mathrm{t} 008 \\
(1)\end{array}$ & {$[41]$} \\
\hline $\begin{array}{l}\text { San } \\
\text { Antonio } \\
\text { de Areco, } \\
\text { Argentina }\end{array}$ & 2008 & $\begin{array}{l}\text { Healthy } \\
\text { kindergarteners }\end{array}$ & $\begin{array}{l}\text { Nares, axillae, } \\
\text { inguinal, or } \\
\text { pharynx (nb) }\end{array}$ & $\begin{array}{l}14 / 316 \\
(4.4 \%)\end{array}$ & $29 \%$ & $\begin{array}{l}\text { All SCCmec type IV; } 8 \text { closely related } \\
\text { by PFGE }\end{array}$ & [42] \\
\hline $\begin{array}{l}\text { Cartagena, } \\
\text { Colombia }\end{array}$ & 2009 & $\begin{array}{l}\text { Healthy children, } \\
2-6 \text { years old }\end{array}$ & Nares (unk) & $\begin{array}{l}5 / 104 \\
\quad(4.8 \%)\end{array}$ & $100 \%$ & $\begin{array}{l}\text { SCCmec type IV (2); SCCmec type II } \\
\text { (1); SCCmec type I (2) }\end{array}$ & [43] \\
\hline $\begin{array}{r}\text { Siem Reap, } \\
\text { Cambodia }\end{array}$ & 2008 & $\begin{array}{l}\text { Healthy children } \\
\text { at doctor's } \\
\text { visits }\end{array}$ & Nares (nb) & $\begin{array}{r}87 / 2,485 \\
(3.5 \%)\end{array}$ & NT & $\begin{array}{l}\text { ST834 (80); ST121 (2); ST188 (3); } \\
\text { ST45 (1); ST9 (1) }\end{array}$ & [44] \\
\hline $\begin{array}{l}\text { Hamandan, } \\
\text { Iran }\end{array}$ & $2007-2008$ & $\begin{array}{l}\text { Healthy children, } \\
1-6 \text { years old at } \\
27 \text { day care } \\
\text { centers }\end{array}$ & Nares (nb) & $\begin{array}{l}6 / 500 \\
(4.1 \%)\end{array}$ & NT & NT & {$[45]$} \\
\hline $\begin{array}{l}\text { Negev } \\
\text { region, } \\
\text { Israel }\end{array}$ & $2005-2006$ & $\begin{array}{l}\text { Children } \\
2-12 \text { months } \\
\text { old at any of } 5 \\
\text { doctors' visits }\end{array}$ & Nares (unk) & $\begin{array}{l}32 / 553 \\
(5.7 \%)\end{array}$ & $0 \%$ & $\begin{array}{l}\text { ST916 (1); ST30 (1); ST911 (1); } \\
\text { ST228 (1); ST5 (1); CC913 (16); } \\
\text { ST247 (1); ST45 (3); other (7) }\end{array}$ & [46] \\
\hline Taiwan & 2005-2008 & $\begin{array}{l}\text { Healthy children } \\
2-60 \text { months } \\
\text { old at clinic } \\
\text { visits }\end{array}$ & $\begin{array}{l}\text { Nares or } \\
\text { nasopharynx } \\
\text { (unk) }\end{array}$ & $\begin{array}{c}473 / 6,057 \\
(7.8 \%)\end{array}$ & $29 \%$ & $\begin{array}{l}12 \text { PFGE types; ST59/V } \mathrm{V}_{\mathrm{T}} / p v l+ \\
(22.8 \%) ; \mathrm{ST} 59 / \mathrm{IV} / p v l-(59.2 \%) \\
\text { other }(18 \%)\end{array}$ & {$[47]$} \\
\hline Taiwan & 2004-2006 & $\begin{array}{l}\text { Healthy children } \\
14 \text { years or } \\
\text { younger }\end{array}$ & Nares (nb) & $\begin{array}{c}131 / 1,615 \\
(8.1 \%)\end{array}$ & $19.1 \%$ & ST59 (111); ST338 (1); other ST (19) & {$[48]$} \\
\hline Taiwan & 2007-2009 & $\begin{array}{l}\text { Healthy children } \\
14 \text { years or } \\
\text { younger }\end{array}$ & Nares (nb) & $\begin{array}{r}240 / 1,585 \\
(15.1 \%)\end{array}$ & $40.8 \%$ & $\begin{array}{l}\text { ST59 (209); ST338 (15); other ST } \\
\text { (16) }\end{array}$ & {$[48]$} \\
\hline
\end{tabular}

$N T$ not tested, $S T$ sequence type

System used to identify strain types when data were available: ST/SCCmec type/pvl+ (presence) or $p v l-($ absence)/spa type

${ }^{a}(n b)$ indicates that broth enrichment culture was not used; $(b)$ indicates that broth enrichment culture was used; (unk) indicates that there was no indication if broth enrichment was used 
known if these risk factors apply to children in other parts of the U.S.

In St. Louis, in a 6-month period in 2006-2007, among children tested for $S$. aureus nasal colonization, a selfreported SSTI occurred in $23 \%$ (6/26) of those with MRSA colonization compared with $8 \%(16 / 194)$ with MSSA and $7 \%$ (34/474) with no S. aureus. Independent risk factors for SSTI included SSTI in a household contact during the 6-month study period [adjusted OR (aOR) 7.6 (95\% CI 3.6, 16.4)] and a history of SSTI in the index child in the year prior to enrollment [aOR 5.3 (95\% CI 2.2, 13.1)]. Curiously, MRSA nasal carriage was not significantly associated with SSTI risk [aOR $2.8(95 \%$ CI 0.9, 8.6)] [55•]. However, among 3,140 children admitted to the Johns Hopkins PICU, those without nasal carriage of MRSA at admission were less likely $(1.4 \%)$ to develop a MRSA infection during hospitalization or after discharge than those with colonization on admission (8.5\%) (RR 5.9, $95 \%$ CI 3.4-10.1) [57]. A follow-up study that included self-report and chart abstraction to identify MRSA infections among patients with MRSA colonization during $(n=128)$ or prior to $(n=40)$ the index PICU stay, $9.5 \%$ had a MRSA infection in the year after hospital discharge [58]. Further research on the importance of MRSA nasal colonization in healthy children as an independent risk factor for subsequent MRSA infection is needed. In addition, the reasons that very young children are at elevated risk for MRSA infections relative to older children requires further research. For example, it is possible that the use of diapers may increase the risk of CAMRSA carriage and infection.

\section{Cystic Fibrosis (CF), MRSA Carriage, and Disease Progression}

Among CF patients, chronic lower respiratory colonization by $S$. aureus is common and has long been recognized. For this reason, surveillance of respiratory secretions for $S$. aureus and other pathogens is often routinely performed. In the U.S., the prevalence of MRSA carriage in respiratory secretions increased from $7.3 \%$ in 2001 to $25.9 \%$ in 2011 [59], although there has been variability at different centers.

Some evidence suggests that MRSA carriage, and perhaps $p v l+$ MRSA carriage, may increase the risk of more rapid progression of illness and death although the importance of these observations in patients with $\mathrm{CF}$ is controversial. At the St. Louis Children's Hospital in 2001-2004, six pediatric CF patients carried $p v l+$ strains of MRSA. These six patients were at higher risk for hospital admission requiring intravenous antibiotics, for focal lung infiltrates, and for a more rapid decrease in $\mathrm{FEV}_{1}$ in the year following isolation of MRSA in the sputum than $34 \mathrm{CF}$ patients colonized with MRSA that was not $p v l+$
[60]. In contrast, a 2-center study showed that in 2004-2005, there was no difference in the likelihood of having a $p v l+$ MRSA isolate obtained from the respiratory secretions of a CF patient with a CF exacerbation (3/11) or from a routine surveillance culture $(7 / 23)(p=1.0)$ [61].

MRSA infection in patients who were 6-17 years of age in the Epidemiologic Study of Cystic Fibrosis during 2001 was associated with more airflow obstruction $\left(\mathrm{FEV}_{1}\right.$ $80.7 \%$ predicted) compared with patients with MSSA infection $\left(\mathrm{FEV}_{1} 89.4 \%\right.$ predicted) [62]. Similarly, using the CF Foundation Patient Registry in 2003-2006, MRSA infection was a risk factor for lack of recovery of $\mathrm{FEV}_{1}$ after an exacerbation of CF [63]. Even more striking, among 19,833 U.S. CF patients aged 6-45 years in 1996-2006 in the CF Foundation Patient Registry, persistent MRSA infection was associated with an increased risk of death (18.3 vs. 27.7 deaths per 1,000 patient-years). The adjusted hazard ratio of death in MRSA colonized patients was 1.27 (95\% CI 1.11-1.45). However, transient MRSA carriage that cleared within 1 year did not confer an increased risk of death [64*0].

Not all studies have supported the association of MRSA colonization with a more rapid progression of disease in $\mathrm{CF}$ patients. In $120 \mathrm{CF}$ patients with MRSA isolated from sputum in North Carolina in 2005-2007, 17 \% of MRSA isolates were $p v l+$ and carried SCCmec type IV. FEV percent predicted did not differ among patients colonized with MRSA or with MSSA, even after adjusting for Pseudomonas colonization, age, and gender. While MRSA patients did require more pulmonary maintenance therapy (i.e., mucolytics, inhaled steroids, and chronic antimicrobial suppressive therapy), they did not require a greater number of antibiotic courses than did MSSA patients [65]. In another cohort, MRSA-colonized patients had a faster decline in lung function even before acquisition of MRSA, suggesting that MRSA was not the cause of this decline but may have been a proxy marker [66].

\section{Invasive and Complicated Infections in the General Pediatric Population}

While the majority of MRSA infections in children are uncomplicated SSTIs, deep tissue and invasive infections were increasingly caused by MRSA in 1995-2010. Many studies of these infections unfortunately lack MRSA genotyping data.

The incidence of pediatric retropharyngeal abscesses at a Detroit hospital in 2004-2010 increased 2.8-fold compared with 1993-2003 (4.94 vs. 13.8 per 10,000 admissions). In the latter period, S. aureus was found in $38 \%$ $(25 / 66)$ of cultures with growth, compared with only $4.9 \%$ (2/41) in 1993-2003. MRSA accounted for $64 \%(16 / 25)$ of 
S. aureus isolates in 2004-2010, and none in 1993-2003 [67•]. At Emory University in Atlanta in 2004-2009, MRSA was isolated from $42 \%(49 / 118)$ of communityonset deep neck space abscesses, while an additional $30 \%$ $(35 / 118)$ were caused by MSSA. Children $<16$ months of age were more likely than older children to have an abscess caused by MRSA or any S. aureus [68]. In a review of 74 pediatric patients with 76 neck abscesses in Iowa in 2000-2010, $12 \%$ grew MRSA and $31 \%$ grew MSSA. There was only one MRSA abscess in 2000-2004 and seven in 2005-2010 [69]. Similar results were obtained in a study from Toronto, Canada [70]. Thus, with the emergence of USA300, S. aureus has become a more common cause of pediatric neck abscesses.

Necrotizing MRSA pneumonia complicating bacteremia or previous viral respiratory infection emerged as a sometimes fatal syndrome among previously healthy children in the era of CA-MRSA in the U.S. and elsewhere [4, 71, 72]. Among 838 U.S. pediatric patients with H1N1 influenza A infection admitted to PICUs in 2009-2010, $8.5 \%(71 / 838)$ also had S. aureus pneumonia, of whom $48 \%$ (34/71) had MRSA strains. Among 251 previously healthy children with influenza A infection, infection with a MRSA isolate $<72 \mathrm{~h}$ after PICU admission was an independent risk factor for death [73]. This study suggests that coinfection of influenza and MRSA, when occurring prior to ICU admission, results in severe pulmonary disease.

Cases of CA-MRSA and HA-MRSA necrotizing fasciitis in children with sometimes fatal outcome have been reported since 2009 in the U.S. [74, 75], and other countries [7679]. Bone and joint CA-MRSA infections have also been reported in previously healthy children in the U.S. [80, 81] and elsewhere [82], as have orbital abscesses [83-86].

At some centers, CA-MRSA strains have come to predominate among causative isolates of MRSA causing pediatric catheter-associated bacteremia (CLABSI). For example, at Texas Children's Hospital in 2001-2007, USA300 was isolated in 21/29 (72\%) of MRSA cases of CLABSI. In MRSA CLABSI cases, prolonged bacteremia was more common than in MSSA CLABSI, but there was no difference in the frequency of complications of endocarditis caused by USA300 or non-USA300 S. aureus [87].

Other severe and complicated pediatric cases of MRSA bacteremia have been reported since 2010 in diverse locations including Washington, DC [88], Hawaii [89], Chicago [90], and abroad [91].

\section{Recurrent MRSA Infections}

Frequent recurrence of MRSA infections, both invasive and non-invasive, has been noted in studies of children. As among adults, recurrence of MRSA infections in children is common, ranging from 9 to $>50 \%$ within a year. However, studies have used differing methods to detect recurrence, and few studies have assessed genetic data to determine if recurrent infections are due to the same MRSA strain types.

At the Akron Children's Hospital ED, of 308 individuals $<21$ years of age (median age 7 years) treated for one or more skin abscesses (79\% of which were caused by MRSA) in January-June 2007, $14 \%$ presented for at least one additional abscess during the study period. Also, among the 192 patients with available data, $43 \%(82 / 192)$ had reported a history of a previous skin abscess [92].

A recurrent self-reported SSTI occurred within 1 year in $>50 \%$ of subjects in a study comparing two decolonization regimens in children who at baseline had a $S$. aureus SSTI (MSSA or MRSA) with subsequent $S$. aureus colonization [93•].

Although the predominant MRSA strain types differ in Taiwan, a study of recurrent infections in children there is noteworthy. In 2004-2006, of 66 paired isolates from an initial and a recurrent MRSA infection in individual children, $69.7 \%$ (46/66) were genotypically indistinguishable by PFGE, and $19.7 \%$ (13/66) differed by $<4$ bands. Distinct strain types were identified in an initial and recurrent infection in $7(10.6 \%)$ paired isolates. When an initial MRSA infection was caused by a $p v l+$ strain, recurrence with the same strain was more likely [94].

Further research is needed to assess the risk factors for recurrent MRSA infection in children, whether recurrence is more common with certain strain types of MRSA, the relationship of prolonged colonization and recurrence and the phenomenon of recurrent MRSA infections at different anatomic sites.

\section{Treatment of Pediatric MRSA Infections}

In 2011, the Infectious Disease Society of America published a treatment Guideline for MRSA infections in pediatric and adult infections. These Guidelines recommend the use of incision and drainage for all purulent SSTIs combined with antimicrobial drug therapy for lesions that are large or are accompanied by systemic symptoms. Drugs of choice for uncomplicated SSTIs should be chosen based on local trends in S. aureus epidemiology, but options include TMP-SMX [trimethoprim 4-6 (mg/kg)/dose, sulfamethoxazole $20-30(\mathrm{mg} / \mathrm{kg}) / \mathrm{dose}$ PO every $12 \mathrm{~h}]$, clindamycin $[10-13(\mathrm{mg} / \mathrm{kg}) /$ dose PO every $6-8 \mathrm{~h}$, not to exceed $40(\mathrm{mg} / \mathrm{kg}) / \mathrm{day}]$, or, only for those greater than 8 years of age, either doxycycline [ $\leq 45 \mathrm{~kg}: 2(\mathrm{mg} / \mathrm{kg}) /$ dose PO every $12 \mathrm{~h} ;>45 \mathrm{~kg}$ : $100 \mathrm{mg}$ BID] or minocycline $[4 \mathrm{mg} / \mathrm{kg} \mathrm{PO} \times 1$, then 
$2(\mathrm{mg} / \mathrm{kg}) /$ dose PO every $12 \mathrm{~h}]$ [95••]. Here, we review recent reports assessing optimal therapies for MRSA infections in children.

In September 2006-May 2009 at Johns Hopkins University, 200 immunocompetent children with uncomplicated, purulent SSTIs treated as outpatients were randomized in a blinded study to receive cephalexin or clindamycin. There was no significant difference in clinical improvement 7 days later (94 vs. $97 \%$ favorable outcomes), regardless of the size of the lesion. Among enrollees, 127/200 (64\%) underwent incision and drainage, 2/200 (1\%) had a needle aspiration, and 66/200 (33\%) had draining pus at presentation with no drainage procedure. Of the enrollees, $69 \%$ had MRSA cultured. Three months later, recurrent SSTIs were self-reported or identified in medical records in $18 \%$ of subjects $(21 \%$ of MRSA patients and $16 \%$ of MSSA) [96].

Although the Hopkins study [96] suggests that antibiotic therapy may not be necessary for improved outcome of therapy for an uncomplicated CA-MRSA SSTI, effective antibiotic therapy may decrease the incidence of recurrent infections. In a double-blind randomized controlled trial among children ( 3 months to 18 years of age) in St. Louis, there was no significant difference in treatment failure in patients with uncomplicated fluctuant SSTIs after incision and drainage who were given TMP-SMX $(4.1 \%, 3 / 73)$ or placebo $(5.3 \%, 4 / 76)$. Eighty percent of recovered pathogens were MRSA and $9 \%$ were MSSA. There was a higher rate of recurrent SSTI in the placebo than the TMPSMX group within the first 10 days of follow-up (26.4 vs. $12.9 \%)$, but not after 3 months (28.8 vs. $28.3 \%$ ) [97].

In a study of 6,407 children 0-17 years of age in 2004-2007 in Tennessee with Medicaid insurance coverage who had an SSTI, clindamycin had a smaller chance of treatment failure than either TMP-SMX (aOR 1.92, $95 \%$ CI 1.49-2.47) or $\beta$-lactams (aOR 2.23, $95 \%$ CI 1.71-2.90). Recurrence was also more likely with TMPSMX (aHR 1.26, $95 \%$ CI 1.06-1.49) or $\beta$-lactams (aHR $1.42,95 \%$ CI 1.19-1.69) compared with clindamycin therapy [98].

In summary, incision and drainage and wound care may be more important than an antibiotic active against $S$. aureus in pediatric uncomplicated SSTIs, although antimicrobial therapy, and perhaps clindamycin more than TMP-SMX, may decrease the incidence of recurrent infections.

\section{Prevention}

It is not clear under what circumstances decolonization should be attempted in children who have MRSA infections. Also, the optimal regimen for decolonization is not established, and adverse effects of decolonization have not been fully explored, although two recent studies have added to our knowledge about decolonization.

In an open-label trial of pediatric $(n=193)$ and adult $(n=107)$ patients who had a S. aureus SSTI in 2007-2009 in St. Louis, intranasal mupirocin twice daily with a daily 15-min bleach bath for 5 days resulted in superior eradication of $S$. aureus after 4 months in the inguinal folds, axillae, and/or nares $(71 \%)$ compared with a 5-day regimen of either $4 \%$ chlorhexidine baths plus mupirocin $(54 \%)$ or intranasal mupirocin alone $(56 \%)$. In each of these three intervention groups, and in a control group (48\% eradication), hygiene education was provided. In all groups combined, recurrent SSTIs were self-reported in $36 \%$ of participants at 4 months [99••].

Despite the apparent decolonization of many participants, recurrent SSTIs were very common, suggesting that a single decolonization regimen is not likely to prevent recurrent disease. Weaknesses of this study included lack of measurement of adherence, lack of strain typing, and only self-report of recurrent infections.

No significant difference was found in eradication of S. aureus carriage among 183 children after treatment for a S. aureus SSTI who were randomized to a 5-day decolonization regimen of $4 \%$ chlorhexidine baths plus intranasal mupirocin in the patients alone (50\% at 1 month; $54 \%$ at 1 year) or to the same regimen applied to the entire household of the patient (51\% at 1 month; $66 \%$ at 1 year). However, self-reported recurrent SSTIs at 12 months were more common in the patient-only decolonization group (72\%) than in the household decolonization group $(52 \%)(p=0.02)[93 \bullet]$.

Thus, decolonization regimens applied to all individuals within a household may have superior efficacy in preventing recurrent SSTIs in a patient who had a $S$. aureus SSTI, but further studies powered to assess this outcome are necessary. Further studies are needed to determine which patients benefit from decolonization, and, in particular, which patients are at highest risk for recurrent disease. In addition, studies utilizing mupirocin or another antimicrobial for decolonization must assess the potential unintended consequence of emerging antibiotic resistance to these agents. Although decolonization may provide some benefit, control of $S$. aureus will not likely be achieved until effective $S$. aureus vaccines are developed and tested [100].

\section{Conclusion}

In 2000-2010, the molecular and clinical epidemiology of pediatric MRSA infections was transformed in the United States and Canada. This was driven by an epidemic of 
CA-MRSA SSTIs and the emergence of the USA300 pulsotype of MRSA in the community and in the health care setting. Additional research is needed in NICUs, among CF patients, in households, and in other community settings to determine risk factors for carriage, transmission, and infection with MRSA. Obesity should be the subject of further research given the high prevalence of both obesity and CA-MRSA in U.S. children. Continued surveillance of MRSA strains is necessary to anticipate changes in antimicrobial susceptibilities and trends in strain replacement. Regimens for the prevention of recurrent MRSA infection, such as decolonization, and the optimal choice of therapy of uncomplicated SSTIs must be clarified, in particular the risks and benefits of routine antibiotic therapy in addition to incision and drainage. A vaccine is likely needed to control MRSA among children.

Disclosure Michael Z. David and Robert S. Daum declare that they have no conflicts of interest.

Ethical standards This article does not contain any studies with human or animal subjects performed by any of the authors.

\section{References}

Papers of particular interest, published recently, have been highlighted as:

- Of importance

.- Of major importance

1. Lowy FD. Staphylococcus aureus infections. N Engl J Med. 1998;339:520-32.

2. Herold BC, Immergluck LC, Maranan MC, et al. Communityacquired methicillin-resistant Staphylococcus aureus in children with no identified predisposing risk. JAMA. 1998;279:593-8.

3. Centers for Disease Control and Prevention (CDC). Four pediatric deaths from community-acquired methicillin-resistant Staphylococcus aureus-Minnesota and North Dakota, 1997-1999. MMWR Morb Mortal Wkly Rep. 1999;48:707-10.

4. David MZ, Daum RS. Community-associated methicillin-resistant Staphylococcus aureus: epidemiology and clinical consequences of an emerging epidemic. Clin Microbiol Rev. 2010;23:616-87.

5. Naimi TS, LeDell KH, Como-Sabetti K, et al. Comparison of community- and health care-associated methicillin-resistant Staphylococcus aureus infection. JAMA. 2003;290:2976-84.

6. Tenover FC, Goering RV. Methicillin-resistant Staphylococcus aureus strain USA300: origin and epidemiology. J Antimicrob Chemother. 2009;64:441-6.

7. Chen KT, Huard RC, Della-Latta P, Saiman L. Prevalence of methicillin-sensitive and methicillin-resistant Staphylococcus aureus in pregnant women. Obstet Gynecol. 2006;108:482-7.

8. Top KA, Huard RC, Fox Z, et al. Trends in methicillin-resistant Staphylococcus aureus anovaginal colonization in pregnant women in 2005 versus 2009. J Clin Microbiol. 2010;48:3675-80.

9. Ghanim N, Alchyib O, Morrish D, et al. Maternal-neonatal outcome with Staphylococcus aureus rectovaginal colonization. J Reprod Med. 2011;56:421-4.
10. Creech CB, Litzner B, Talbot TR, Schaffner W. Frequency of detection of methicillin-resistant Staphylococcus aureus from rectovaginal swabs in pregnant women. Am J Infect Control. 2010;38:72-4.

11. Andrews WW, Schelonka R, Waites K. Genital tract methicillinresistant Staphylococcus aureus: risk of vertical transmission in pregnant women. Obstet Gynecol. 2008;111:113-8.

12. Reusch M, Ghosh P, Ham C, et al. Prevalence of MRSA colonization in peripartum mothers and their newborn infants. Scand J Infect Dis. 2008;40:667-71.

13. Lazenby GB, Soper DE, Beardsley W, Salgado CD. Methicillinresistant Staphylococcus aureus colonization among women admitted for preterm delivery. Am J Obstet Gynecol 2012;206: 329.e1-e5.

14. Tomlinson MW, Schmidt NM, Rourke JW Jr. McDonald J: Rectovaginal Staphylococcus aureus colonization: is it a neonatal threat? Am J Perinatol. 2011;28:673-6.

15. Beigi R, Hanrahan J. Staphylococcus aureus and MRSA colonization rates among gravidas admitted to labor and delivery: a pilot study. Infect Dis Obstet Gynecol. 2007;2007:70876.

16. Volk L, Thomson T, Chhangani P, et al. Methicillin-resistant Staphylococcus aureus nasal colonization among women admitted to labor and delivery and their newborn infants. Infect Control Hosp Epidemiol. 2011;32:1045-6.

17. - Jimenez-Truque N, Tedeschi S, Saye EJ, et al. Relationship between maternal and neonatal Staphylococcus aureus colonization. Pediatrics 2012;129:e1252-9. A large study from Memphis, TN, showing that, while infants and mothers may carry concordant MRSA strain types, this is first noted some time after birth, suggesting that peripartum MRSA transmission is not common.

18. Chatzakis E, Scoulica E, Papageorgiou N, et al. Infant colonization by Staphylococcus aureus: role of maternal carriage. Eur J Clin Microbiol Infect Dis. 2011;30:1111-7.

19. Gries DM, Zemzars TF, Gibson KA, et al. A pilot study to assess frequency of carriage and routes of acquisition of Staphylococcus aureus by healthy infants. Am J Infect Control. 2009; 37:598-600.

20. - Carey AJ, Della-Latta P, Huard R, et al. Changes in the molecular epidemiological characteristics of methicillin-resistant Staphylococcus aureus in a neonatal intensive care unit. Infect Control Hosp Epidemiol 2010;31:613-9. An early report of the strain shift in a large NICU on the East Coast of the United States over a 9-year period from HA-MRSA (USA100) to USA300, the predominant CA-MRSA strain type in the U.S., based on culture results of more than 1,300 infants.

21. Hermos CR, Sandora TJ, Williams LE, et al. Changing epidemiology of methicillin-resistant Staphylococcus aureus colonization in paediatric intensive-care units. Epidemiol Infect. 2012;29:1-10.

22. Rana D, Abughali N, Kumar D, et al. Staphylococcus aureus, including community-acquired methicillin-resistant $S$. aureus, in a level III NICU: 2001 to 2008. Am J Perinatol. 2012;29:401-8.

23. Shane AL, Stoll BJ. Recent developments and current issues in the epidemiology, diagnosis, and management of bacterial and fungal neonatal sepsis. Am J Perinatol. 2013;30:131-41.

24. Gregory ML, Eichenwald EC, Puopolo KM. Seven-year experience with a surveillance program to reduce methicillin-resistant Staphylococcus aureus colonization in a neonatal intensive care unit. Pediatrics. 2009;123:e790-6.

25. Myers PJ, Marcinak J, David MZ, et al. Universal admission screening for methicillin-resistant Staphylococcus aureus in a level IIID neonatal intensive care unit: the first 9 months. Infect Control Hosp Epidemiol. 2011;32:398-400.

26. - Milstone AM, Carroll KC, Ross T, et al. Community-associated methicillin-resistant Staphylococcus aureus strains in 
pediatric intensive care unit. Emerg Infect Dis 2010;16:647-55. An unusual study of MRSA in a PICU including genotyping of collected strains in 2007-2008 demonstrating the predominance of CA-MRSA.

27. Farr AM, Aden B, Weiss D, et al. Trends in hospitalization for community-associated methicillin-resistant Staphylococcus aureus in New York City, 1997-2006: data from New York State's Statewide Planning and Research Cooperative System. Infect Control Hosp Epidemiol. 2012;33:725-31.

28. Hudson LO, Murphy CR, Spratt BG, et al. Differences in methicillin-resistant Staphylococcus aureus strains isolated from pediatric and adult patients from hospitals in a large county in California. J Clin Microbiol. 2012;50:573-9.

29. Dukic VM, Lauderdale DS, Wilder J, et al. Epidemics of community-associated methicillin-resistant Staphylococcus aureus in the United States: a meta-analysis. PLoS ONE. 2013; 8(1):e52722.

30. Frei CR, Makos BR, Daniels KR, Oramasionwu CU. Emergence of community-acquired methicillin-resistant Staphylococcus aureus skin and soft tissue infections as a common cause of hospitalization in United States children. J Pediatr Surg. 2010; 45:1967-74.

31. Lautz TB, Raval MV, Barsness KA. Increasing national burden of hospitalizations for skin and soft tissue infections in children. J Pediatr Surg. 2011;46:1935-41.

32. Herigon JC, Hersh AL, Gerber JS, et al. Antibiotic management of Staphylococcus aureus infections in US children's hospitals, 1999-2008. Pediatrics. 2010;125:e1294-300.

33. Matlow A, Forgie S, Pelude L, et al. National surveillance of methicillin-resistant Staphylococcus aureus among hospitalized pediatric patients in Canadian acute care facilities, 1995-2007. Pediatr Infect Dis J. 2012;31:814-20.

34. • Gutierrez K, Halpern MS, Sarnquist C, et al. Staphylococcal infections in children, California, USA, 1985-2009. Emerg Infect Dis 2013;19:10-20. Among the largest and most thorough population-based studies of $S$. aureus infections in hospitalized children ever reported, this 25-year review of MSSA and MRSA infections demonstrated that there was a massive increase in the S. aureus-associated hospitalization rate in California children from the 1980s to 2006. This rise was fueled by the CA-MRSA epidemic, which disproportionately affected children $<3$ years of age and black children, as demonstrated by a state hospital discharge database.

35. Humphries RM, Deville JG. The Changing Epidemiology of Methicillin-Resistant Staphylococcus aureus in Pediatric Wound Cultures: 10-Year Experience. Clin Pediatr (Phila). 2012;52(6): $570-3$.

36. Miller MB, Weber DJ, Goodrich JS, et al. Prevalence and risk factor analysis for methicillin-resistant Staphylococcus aureus nasal colonization in children attending child care centers. J Clin Microbiol. 2011;49:1041-7.

37. Hewlett AL, Falk PS, Hughes KS, Mayhall CG. Epidemiology of methicillin-resistant Staphylococcus aureus in a university medical center day care facility. Infect Control Hosp Epidemiol. 2009;30:985-92.

38. Lee J, Sung JY, Kim YM, et al. Molecular characterization of methicillin-resistant Staphylococcus aureus obtained from the anterior nares of healthy Korean children attending daycare centers. Int J Infect Dis. 2011;15:e558-63.

39. Ho PL, Chiu SS, Chan MY, et al. Molecular epidemiology and nasal carriage of Staphylococcus aureus and methicillin-resistant $\mathrm{S}$. aureus among young children attending day care centers and kindergartens in Hong Kong. J Infect. 2012;64:500-6.

40. Blumental S, Deplano A, Jourdain S, et al. Dynamic pattern and genotypic diversity of Staphylococcus aureus nasopharyngeal carriage in healthy pre-school children. J Antimicrob Chemother. 2013; doi:10.1093/jac/dkt080.

41. Tavares DA, Sá-Leão R, Miragaia M, de Lencastre H. Large screening of CA-MRSA among Staphylococcus aureus colonizing healthy young children living in two areas (urban and rural) of Portugal. BMC Infect Dis. 2010;10:110.

42. Gardella N, Murzicato S, Di Gregorio S, et al. Prevalence and characterization of methicillin-resistant Staphylococcus aureus among healthy children in a city of Argentina. Infect Genet Evol. 2011;11:1066-71.

43. Rebollo-Pérez J, Ordoñez-Tapia C, Herazo-Herazo C, ReyesRamos N. Nasal carriage of Panton Valentine leukocidin-positive methicillin-resistant Staphylococcus aureus in healthy preschool children. Rev Salud Publica (Bogota). 2011;13:824-32.

44. Nickerson EK, Wuthiekanun V, Kumar V, et al. Emergence of community-associated methicillin-resistant Staphylococcus aureus carriage in children in Cambodia. Am J Trop Med Hyg. 2011;84:313-7.

45. Sedighi I, Moez HJ, Alikhani MY. Nasal carriage of methicillin resistant Staphylococcus aureus and their antibiotic susceptibility patterns in children attending day-care centers. Acta Microbiol Immunol Hung. 2011;58:227-34.

46. Adler A, Givon-Lavi N, Moses AE, et al. Carriage of community-associated methicillin-resistant Staphylococcus aureus in a cohort of infants in southern Israel: risk factors and molecular features. J Clin Microbiol. 2010;48:531-8.

47. Chen CJ, Hsu KH, Lin TY, et al. Factors associated with nasal colonization of methicillin-resistant Staphylococcus aureus among healthy children in Taiwan. J Clin Microbiol. 2011;49: $131-7$.

48. Lo WT, Wang CC, Lin WJ, et al. Changes in the nasal colonization with methicillin-resistant Staphylococcus aureus in children: 2004-2009. PLoS ONE. 2010;5(12):e15791.

49. Creech CB 2nd, Kernodle DS, Alsentzer A, et al. Increasing rates of nasal carriage of methicillin-resistant Staphylococcus aureus in healthy children. Pediatr Infect Dis J. 2005;24:617-21.

50. Nerby JM, Gorwitz R, Lesher L, et al. Risk factors for household transmission of community-associated methicillin-resistant Staphylococcus aureus. Pediatr Infect Dis J. 2011;30:927-32.

51. Rafee Y, Abdel-Haq N, Asmar B, et al. Increased prevalence of methicillin-resistant Staphylococcus aureus nasal colonization in household contacts of children with community acquired disease. BMC Infect Dis. 2012;12:45.

52. Miller LG, Eells SJ, Taylor AR, et al. Staphylococcus aureus colonization among household contacts of patients with skin infections: risk factors, strain discordance, and complex ecology. Clin Infect Dis. 2012;54:1523-35.

53. - Mongkolrattanothai K, Gray BM, Mankin P, et al. Simultaneous carriage of multiple genotypes of Staphylococcus aureus in children. J Med Microbiol 2011;60:317-2. Adds to the literature on polyclonal S. aureus carriage, showing that more than one-quarter of 125 tested children prior to surgery in Illinois carried 2 or more distinct strain types.

54. Early GJ, Seifried SE. Risk factors for community-associated Staphylococcus aureus skin infection in children of Maui. Hawaii J Med Public Health. 2012;71(8):218-23.

55. - Fritz SA, Epplin EK, Garbutt J, Storch GA. Skin infection in children colonized with community-associated methicillinresistant Staphylococcus aureus. J Infect 2009;59:394-401. Although it relies on self-reported skin lesions, this is an excellent study on SSTIs in children in 2006-7 in a Midwestern U.S. city. Identified household contact with an SSTI patient in the previous 6 months and a history of SSTI in the patient himor herself within a year, but not MRSA nasal carriage, as independent risk factors for SSTI. 
56. Schneider-Lindner V, Quach C, Hanley JA, Suissa S. Antibacterial drugs and the risk of community-associated methicillinresistant Staphylococcus aureus in children. Arch Pediatr Adolesc Med. 2011;165:1107-14.

57. Milstone AM, Goldner BW, Ross T, et al. Methicillin-resistant Staphylococcus aureus colonization and risk of subsequent infection in critically ill children: importance of preventing nosocomial methicillin-resistant Staphylococcus aureus transmission. Clin Infect Dis. 2011;53:853-9.

58. Advani S, Sengupta A, Milstone AM. Postdischarge surveillance to identify subsequent methicillin-resistant Staphylococcus aureus infections in colonized children. Am J Infect Control. 2013; doi:10.1016/j.ajic.2012.12.016.

59. Cystic Fibrosis Foundation Patient Registry 2011 Annual Data Report. Bethesda, MD, Cystic Fibrosis Foundation; 2012.

60. Elizur A, Orscheln RC, Ferkol TW, et al. Panton-Valentine Leukocidin-positive methicillin-resistant Staphylococcus aureus lung infection in patients with cystic fibrosis. Chest. 2007;131: $1718-25$.

61. Glikman D, Siegel JD, David MZ, et al. Complex molecular epidemiology of methicillin-resistant Staphylococcus aureus isolates from children with cystic fibrosis in the era of epidemic community-associated methicillin-resistant $S$. aureus. Chest. 2008;133:1381-7.

62. Ren CL, Morgan WJ, Konstan MW, et al. Presence of methicillin resistant Staphylococcus aureus in respiratory cultures from cystic fibrosis patients is associated with lower lung function. Pediatr Pulmonol. 2007;42:513-8.

63. Sanders DB, Bittner RC, Rosenfeld M, et al. Failure to recover to baseline pulmonary function after cystic fibrosis pulmonary exacerbation. Am J Respir Crit Care Med. 2010;182:627-32.

64. •• Dasenbrook EC, Checkley W, Merlo CA, et al. Association between respiratory tract methicillin-resistant Staphylococcus aureus and survival in cystic fibrosis. JAMA. 2010;303: 2386-92. A study of nearly 20,000 pediatric and adult CF patients demonstrating an association of increased hazard of death with persistent MRSA carriage in the respiratory tract.

65. Muhlebach MS, Miller M, LaVange LM, et al. Treatment intensity and characteristics of MRSA infection in CF. J Cyst Fibros. 2011;10:201-6.

66. Sawicki GS, Rasouliyan L, Ren CL. The impact of MRSA on lung function in patients with cystic fibrosis. Am J Respir Crit Care Med. 2009;179:734-5.

67. • Abdel-Haq N, Quezada M, Asmar BI. Retropharyngeal abscess in children: the rising incidence of methicillin-resistant Staphylococcus aureus. Pediatr Infect Dis J 2012;31:696-9. A 10-year study of pediatric retropharyngeal abscesses in a single medical center showing a marked rise in the percent of lesions caused by S. aureus and caused by MRSA between 1993 and 2003. This is a clear demonstration of a shift in the etiology of a relatively common, life-threatening childhood infection in the CA-MRSA era.

68. Duggal P, Naseri I, Sobol SE. The increased risk of communityacquired methicillin-resistant Staphylococcus aureus neck abscesses in young children. Laryngoscope. 2011;121:51-5.

69. Walker PC, Karnell LH, Ziebold C, Kacmarynski DS. Changing microbiology of pediatric neck abscesses in Iowa 2000-2010. Laryngoscope. 2013;123:249-52.

70. Alexander AJ, Richardson SE, Sharma A, Campisi P. The increasing prevalence of clindamycin resistance in Staphylococcus aureus isolates in children with head and neck abscesses. Can J Infect Dis Med Microbiol. 2011;22:49-51.

71. Obando I, Valderrabanos ES, Millan JA, Neth OW. Necrotising pneumonia due to influenza A (H1N1) and community-acquired methicillin-resistant Staphylococcus aureus clone USA300: successful management of the first documented paediatric case. Arch Dis Child. 2010;95:305-6.

72. Kimata T, Tsuji S, Yoshimura K, et al. Methicillin-resistant Staphylococcus aureus-related glomerulonephritis in a child. Pediatr Nephrol. 2012;27:2149-52.

73. Randolph AG, Vaughn F, Sullivan R, et al. Critically ill children during the 2009-2010 influenza pandemic in the United States. Pediatrics. 2011;128:e1450-8.

74. Lalich IJ, Sam-Agudu NA. Community-acquired methicillinresistant Staphylococcus aureus necrotizing fasciitis in a healthy adolescent male. Minn Med. 2010;93:44-6.

75. Fitzgerald CJ, Pranikoff TV, Ross GA, et al. Purpura fulminans caused by community-associated methicillin-resistant Staphylococcus aureus. Am J Emerg Med 2012;30:1013.e1-4.

76. Walls T, Williams G, Adams S, et al. Neonatal necrotizing fasciitis following superficial skin infection with communityassociated methicillin-resistant Staphylococcus aureus. J Paediatr Child Health. 2011;47:918-20.

77. Gouveia C, Gavino A, Bouchami O, et al. Community-associated methicillin-resistant Staphylococcus aureus lacking PVL, as a cause of severe invasive infection treated with linezolid. Case Rep Pediatr. 2013;2013:727824.

78. Carvalho Ferreira D, Cisne Frota AC, Cavalcante FS, et al. Necrotizing fasciitis secondary to community pneumonia by Panton-Valentine leukocidin-positive methicillin-resistant Staphylococcus aureus. Am J Respir Crit Care Med. 2012; 186:202-3.

79. Verma P, Pandhi D, Yadav P, Dhawan AK. Neonatal purpura fulminans due to methicillin resistant Staphylococcus aureus. Pediatr Dermatol. 2013;30:266-7.

80. Schaub RL, Rodkey ML. Deep vein thrombosis and septic pulmonary emboli with MRSA osteomyelitis in a pediatric patient. Pediatr Emerg Care. 2012;28:911-2.

81. Carrillo-Marquez MA, Hulten KG, Hammerman W, et al. USA300 is the predominant genotype causing Staphylococcus aureus septic arthritis in children. Pediatr Infect Dis J. 2009; 28:1076-80.

82. Bukhari EE, Al-Otaibi FE. Severe community-acquired infection caused by methicillin-resistant Staphylococcus aureus in Saudi Arabian children. Saudi Med J. 2009;30:1595-600.

83. Chung WC, Lin HJ, Foo NP, Chen KT. Infantile orbital abscess caused by community-acquired methicillin-resistant Staphylococcus aureus. J Ophthalmic Inflamm Infect. 2011;1:181-3.

84. Lei TH, Huang YC, Chu YC, et al. Orbital cellulitis caused by community-associated methicillin-resistant Staphylococcus aureus in a previously healthy neonate. J Microbiol Immunol Infect. 2013;46:136-8.

85. Vaska VL, Grimwood K, Gole GA, et al. Community-associated methicillin-resistant Staphylococcus aureus causing orbital cellulitis in Australian children. Pediatr Infect Dis J. 2011;30: 1003-6.

86. Kobayashi D, Givner LB, Yeatts RP, et al. Infantile orbital cellulitis secondary to community-associated methicillin-resistant Staphylococcus aureus. J AAPOS. 2011;15:208-10.

87. Carrillo-Marquez MA, Hulten KG, Mason EO, Kaplan SL. Clinical and molecular epidemiology of Staphylococcus aureus catheter-related bacteremia in children. Pediatr Infect Dis J. 2010;29:410-4.

88. Gaur L, Madan S, Morell V, Arora G. Formation of ventricular aneurysm after endocarditis in a child with methicillin-resistant Staphylococcus aureus (MRSA) bacteremia. Pediatr Cardiol. 2011;32:1062-4.

89. Bowen DK, Mitchell LA, Burnett MW, et al. Spinal epidural abscess due to tropical pyomyositis in immunocompetent adolescents. J Neurosurg Pediatr. 2010;6:33-7. 
90. Hoehn KS, Capouya JD, Daum RS, et al. Lemierre-like syndrome caused by community-associated methicillin-resistant Staphylococcus aureus complicated by hemorrhagic pericarditis. Pediatr Crit Care Med. 2010;11:e32-5.

91. Groome MJ, Albrich WC, Wadula J, et al. Community-onset Staphylococcus aureus bacteraemia in hospitalised African children: high incidence in HIV-infected children and high prevalence of multidrug resistance. Paediatr Int Child Health. 2012;32:140-6.

92. Holsenback H, Smith L, Stevenson MD. Cutaneous abscesses in children: epidemiology in the era of methicillin-resistant Staphylococcus aureus in a pediatric emergency department. Pediatr Emerg Care. 2012;28:684-6.

93. - Fritz SA, Hogan PG, Hayek G, et al. Household versus individual approaches to eradication of community-associated Staphylococcus aureus in children: a randomized trial. Clin Infect Dis 2012;54:743-51. A trial of children after therapy for a S. aureus skin infection to assess the efficacy of individual decolonization compared with decolonization of the index patient plus all household contacts with chlorhexidine baths plus intransal mupirocin ointment; demonstrated that there is little difference in colonization prevalence, but recurrent skin infections may be less common in the subsequent year if all household contacts undergo decolonization.

94. Chen CJ, Su LH, Lin TY, Huang YC. Molecular analysis of repeated methicillin-resistant Staphylococcus aureus infections in children. PLoS ONE. 2010;5(12):e14431.
95. • Liu C, Bayer A, Cosgrove SE, et al. Clinical practice guidelines by the infectious Diseases Society of America for the treatment of methicillin-resistant Staphylococcus aureus infections in adults and children. Clin Infect Dis 2011;52:e18-e55. Erratum in: Clin Infect Dis 2011;53:319. Provides a comprehensive review of the literature on therapy for invasive and noninvasive MRSA infections as well as concrete guidelines for therapy.

96. Chen AE, Carroll KC, Diener-West M, et al. Randomized controlled trial of cephalexin versus clindamycin for uncomplicated pediatric skin infections. Pediatrics. 2011;127:e573-80.

97. Duong M, Markwell S, Peter J, Barenkamp S. Randomized, controlled trial of antibiotics in the management of communityacquired skin abscesses in the pediatric patient. Ann Emerg Med. 2010;55:401-7.

98. Williams DJ, Cooper WO, Kaltenbach LA, et al. Comparative effectiveness of antibiotic treatment strategies for pediatric skin and soft-tissue infections. Pediatrics. 2011;128:e479-87.

99. •• Fritz SA, Camins BC, Eisenstein KA, et al. Effectiveness of measures to eradicate Staphylococcus aureus carriage in patients with community-associated skin and soft-tissue infections: a randomized trial. Infect Control Hosp Epidemiol 2011;32: 872-80. A well-designed, randomized, controlled trial of different regimens to decrease S. aureus carriage prevalence in adults and children in the community.

100. Daum RS, Spellberg B. Progress toward a Staphylococcus aureus vaccine. Clin Infect Dis. 2012;54:560-7. 